\title{
The Implementation of Kirkpatrick's Evaluation Model in the Learning of Initial Value and Boundary Condition Problems
}

\author{
Syamsu Qamar Badu \\ Dept. of Mathematics Education, Gorontalo State University \\ Jl. Jenderal Sudirman No. 6 Kota Gorontalo 96128, Indonesia \\ E-mail: syamsuqb13@yahoo.com \\ Accepted: Oct 11, 2013 Published: Oct 27, 2013 \\ Doi:10.5296/ijld.v3i5.4386 URL: http://dx.doi.org/10.5296/ijld.v3i5.4386
}

\begin{abstract}
This research aimed at describing the implementation of Kirkpatrick's evaluation model in the learning of Initial Value and Boundary Condition Problems. For each of the four different levels in the model, an evaluation was conducted using different instruments. A performance evaluation was conducted to assess the students' product or project. This was a qualitative descriptive study involving 58 students of Mathematics Department, Faculty of mathematics and Natural Sciences, State University of Gorontalo as the sample. The data were collected by means of questionnaire; the reliability was tested through Cronbrach's alpha. Students' learning achievement was scored using a performance rubric. The study shows that Kirkpatrick's Evaluation Model for the learning program of initial Values and Boundary Condition Problems is very effective.
\end{abstract}

Keywords: Kirkpatrick's evaluation model, Performance assessment, Initial value and boundary condition problems

\section{Introduction}

The Initial Value and Boundary Condition Problems is a compulsory subject in Mathematics Department, Faculty of Mathematics and Natural Sciences, State University of Gorontalo. Application of the subject has something to do with computation and modeling system. Given the complex nature of the subject, a specific evaluation for the learning program is necessary to uncover the true competence/potentials of the students, particularly when it comes to the standard of competence. The academic quality of the students can be improved by enhancing the learning quality and evaluation model quality. A good learning system will produce a good learning quality. This highlights the interrelationship of the two aspects. A lecturer or a teacher should not overlook the aspect of evaluation. Evaluation is a continuous process, which serves as the basis for all activities in a good learning process. Evaluation refers to assessment for a specified program. In general, evaluation is defined as a systematic process to determine the value of something (objective, activity, decision, performance, process, individual, and even an object) based on certain criteria. In the learning context, evaluation is defined as a systematic process to determine the achievement level based on the specified learning objectives.

National Study Committee on Evaluation in Stark and Thomas (1994:12) suggests that "evaluation is the process of ascertaining the decision of concern, selecting appropriate information, and collecting and analyzing information in order to report summary data useful to decision makers in selecting among alternatives. This is confirmed by Griffin and Nix (1991:3), suggesting, measurement, assessment, and evaluation are hierarchical. The 
comparison of observation with the criteria is a measurement; the interpretation and description of the evidence is an assessment and the judgment of the value or implication of the behavior is an evaluation.

Evaluation is an inseparable part of the activities in Mathematics learning. A teacher can do many things to collect information on the students' level of achievement. They include giving tests, assignments, oral questions, observation during the teaching-learning session, and portfolio. The activities are conducted not only to determine the students' grade but also to improve the quality of mathematics learning.

Learning evaluation should be conducted in a thorough and sustainable way, involving assessment on the learning process and outcomes. One of important factors that contribute to the achievement of educational objectives is the learning process itself. On the other hand, evaluation and assessment (both on the learning process and on the outcomes in a continuous way) also play a role in encouraging the teaching staffs to improve the quality of learning process.

One of the main components in the education system is assessment. Assessment provides not only a description or information on the students' achievement or mastery of the learnt materials, but also a feedback to the educational program itself. Learning assessment is conducted as a part of decision-making process when it comes to the students' mastery of the materials after they are engaged in the teaching-learning process. In addition, learning assessment is also useful to figure out whether the learning strategy or approach is appropriate or not.

Accordingly, the educational system needs competent teaching staffs that are capable of not only teaching in a good way but also evaluating the learning outcome in an appropriate and effective way based on characteristics of the subject. As a part of the learning program, evaluation must be done in an optimum way. It should not rely merely upon the learning output, but also on the input, output, and quality of the learning process. In both educational sector and learning process, the role of information technology media should not be overlooked. The use of media is an element, which must be considered by the lecturers/teaching staffs in all of the learning activities. Accordingly, learning assessment should not rely merely upon the traditional tests.

Limitation of the traditional tests as the sole decision-making tool when it comes to the students' achievement is that it simply assesses the scientific knowledge. The assessment focuses only on the limited dimension of learning outcomes (knowledge and skills). It cannot be used to assess in-depth reasoning capability. In addition, it is not able to show the real competence of the students (Mokhtari et al., 1996). Another limitation of the traditional tests is that each question generally has a single, absolute answer. It does not focus on the process, but on the outcome; it neither reveals the students' thinking process nor measures all aspects of the teaching-learning process.

Brikerhoff in Mardapi (2000) suggests that there are seven elements of learning evaluation. They are 1) focusing the evaluation, 2) designing the evaluation, 3) collecting information, 4) analyzing and interpreting, 5) reporting information, 6) managing evaluation, and 7) evaluating evaluation. The definition shows that in the early phases, an evaluator must first determine focuses and design of the evaluation.

The objective of evaluation is to obtain accurate and objective information on a program, which has been planned and implemented in the previous phases. The information may come from the process of program implementation, impacts/results, and efficiency. The results of evaluation determine whether the program is successful or not, whether it is going to be continued or stopped, and whether it is going to be used as a basis for the next program or not.

A number of evaluation models have been developed and widely used as strategies or guidelines in the implementation of learning program. They include Kirkpatrick's Evaluation 
Model (Kirkpatrick Four Levels Evaluation Model), 2) CIPP Evaluation Model (context, input, process, and product), and Stake's evaluation model (Model Countenance). This research was focused on Kirkpatrick's Evaluation Model.

From the perspective of its targets in educational sector, evaluation can be classified into macro and micro evaluations. Macro evaluation targets the educational programs, namely, programs that are designed to improve the educational output. Micro evaluation is widely used in classrooms, particularly to find out the students' level of achievement. The learning achievement is not limited only to cognitive one; instead, it involves all of the students' potentials. Therefore, micro evaluation targets the classroom-level learning programs, which are under the lecturer/teacher responsibility (Mardapi, 2000:2).

Kirkpatrick is an expert of training program evaluation in the human resource development context. The evaluation model developed by Kirkpatrick is known as Kirkpatrick's Four Levels Evaluation Model. According to Kirkpatrick (1998), evaluation of the training program effectiveness involves four different levels, namely, Level 1 Reaction, Level 2 Learning, Level 3 Behavior, and Level 4 Outcome.

Evaluation of the trainees' reaction refers to measurement of their level of satisfaction. A training program is regarded effective when it is pleasing and satisfying to the participants, so that they are motivated to learn and to exercise more. In other words, the trainees will be motivated when the training process runs in a satisfactory way and successfully invites gratifying responses from the participants. On the other hand, when the participants feel dissatisfied with the training program, they will not be motivated to proceed to the next sessions.

Kirkpatrick (1998:20) suggests, "Learning can be defined as the extent to which participants change attitudes, improving knowledge, and/or increase skill as a result of attending the program". The studies suggest that the trainers can provide the trainees with three important things, namely, knowledge, attitude, and skills. The trainees are said to get something from the training when they show different attitude, improved knowledge, and improved skills.

Evaluation level 3 (evaluation of behavior) is different from evaluation level 2. Attitude assessment at evaluation level 2 is focused on the change in attitude because of training activities, which are internal in nature; meanwhile, behavioral assessment is focused on the change in behavior after the training participants get back to workplace. The success criteria for evaluation level 3 are changes in attitude when the trainees have been thorough with the training and implement the results. Therefore, behavioral assessment is external in nature. Evaluation level 4 is focused on the outcome of a training program. In the learning context, the evaluation model targets the training outcomes perceived by the students.

Evaluation aims at obtaining a description or information on the outcomes perceived by the students and at finding out the difficulties facing the students during the learning process. It is also closely related to the assessment process, whether it is output or process assessment. It serves to develop a learning program that includes a teaching-learning design. It also serves to specify position (achievement) of a learning program based on certain criteria. In this way, the program can be believable, trustable, and implementable; otherwise, the program needs to be improved or completed.

Evaluation is a main activity that becomes an integral part of the teachers' task in the learning process. Through the assessment, the teacher figures out the learning progress, intelligence, specific talent, social relationship, attitude, and personality of the students. The evaluation itself influences whether the learning objectives have been achieved or not. Therefore, it is important to measure achievement of both the students and the teachers in the teaching-learning process. 
Assessment is the main element of the teaching-learning process. It is a process of collecting information in a systematic and structured way, both in qualitative and quantitative ways. It is used to provide the students with information on their achievement and mastery of the learning subjects (Garfield, 1994). It is also a process to obtain information on mathematic knowledge of the students and their ability to draw a conclusion for a variety of objectives (NCTM, 1995). Assessment has an important vision, namely, as a dynamic process that continuously generates information on the students' progress and achievement based on the learning objectives.

Assessment has a different meaning from evaluation. The Task Group on Assessment a Testing (TGAT) describes assessment as any efforts to assess individual or group performance (Griffin and Nix, 1991:3). Popham (1995:3) defines assessment in educational context as a formal effort to determine the students' status when it comes to a variety of educational interests. Boyer and Ewel in Stark and Thomas (1994:46) suggest that assessment in processes that provide information about individual students, about curricula and programs, about institutions, or about entire systems of institutions. Based on the definitions, it can be concluded that assessment is a process of data interpretation based on certain measurements. Assessment is conducted based on characteristics of the students and the subjects.

This research applied Kirkpatrick's Evaluation Model for the subject of The Initial Value and Boundary Condition Problems in the students of Mathematics Department, Faculty of mathematics and Natural Sciences, State University of Gorontalo. Separate assessment was conducted for each of the four different levels in the model. At the reaction level (evaluating reaction), the learning process involved the use of IT, namely, Maple software, in addition to a number of practice sessions (modeling) to solve the problems related to the subject. At learning evaluation level (evaluating learning), assessment was conducted using performance rubric. At the third level, assessment was conducted to get a description on the students' behavior to the learning activities. Finally, the fourth level was focused more on the outcome (i.e. learning outcome in the students).

Problem of the research was related to the implementation of Kirkpatrick's Evaluation Model in the learning program of The Initial Value and Boundary Condition Problems and with the effectiveness of Kirkpatrick's Evaluation Model based on the assessment conducted for each evaluation aspect. Each aspect or level in the Kirkpatrick's Evaluation Model was assessed or evaluated by using different instruments; the objective was to provide a general description on the students' competence in the subject of the Initial Value and Boundary Condition Problems. The results of evaluation were analyzed in a descriptive way.

\section{Methods}

The research was conducted to provide a description on the implementation of Kirkpatrick's Evaluation Model in learning of The Initial Value and Boundary Condition Problems in the students of Mathematics Department, Faculty of mathematics and Natural Sciences, State University of Gorontalo. This was a descriptive qualitative research. Data on the Kirkpatrick's Evaluation Model was screened using various instruments. For the first level in Kirkpatrick's Evaluation Model, the data were obtained using questionnaire, which had been estimated for reliability using Crombach's Alpha. On the other hand, data on the learning outcomes in the students were obtained based on the assessment conducted during the learning process.

Subjects of the study were the students of Mathematics Department, Faculty of mathematics and Natural Sciences, State University of Gorontalo, exactly 2007/2008 generation that took the subject of Initial Value and Boundary Condition Problems. Population of the study consisted of students in two classrooms, with 58 students as sample.

Procedure of the research referred to the mechanism applied during the research. The research was conducted with the following phases (Table 1). 
Data collection for the research was conducted for each aspect in the Kirkpatrick's Evaluation Model. Each aspect was assessed using different instruments. Evaluation on the learning program of the Initial Value and Boundary Condition Problems was conducted for four aspects, namely, Reaction, Learning, Behavior, and Outcome. Objectiveness of the assessment was the first priority or the first emphasis. For this, each assessment involved performance rubric and different criteria. Evaluation of Reaction was conducted using a reaction sheet in the form of questionnaire to make the process easier and more effective.

Tabel 1. Phases of the research

\begin{tabular}{|c|c|c|}
\hline $\mathrm{No}$ & Research phase & Activities \\
\hline \multirow{4}{*}{1} & \multirow{4}{*}{ Preparatory phase } & Deciding the learning materials \\
\hline & & Formulating technical guide for practice classes \\
\hline & & Preparing the evaluation rubric \\
\hline & & Preparing the questionnaire \\
\hline \multirow[b]{2}{*}{2} & \multirow[b]{2}{*}{ Implementation phase } & $\begin{array}{l}\text { Mechanism of practical activities as a part of process } \\
\text { evaluation }\end{array}$ \\
\hline & & $\begin{array}{l}\text { Assessing the students' project by means of } \\
\text { performance assessment (rubric) as a part of the } \\
\text { learning evaluation }\end{array}$ \\
\hline \multirow{6}{*}{3} & \multirow{6}{*}{ Final phase } & Collecting Data \\
\hline & & Testing Data \\
\hline & & Analyzing data \\
\hline & & Discussing the result of data analysis \\
\hline & & Drafting the research report \\
\hline & & Writing the research article \\
\hline
\end{tabular}

Data on the Learning evaluation were collected by means of performance assessment, namely, performance rubric. The rubric or assessment criteria refer to the description of certain dimensions in the form of value score to determine the students' performance. There were two types of rubric used for performance evaluation. They were holistic rubric to describe the performance quality and analytic rubric to score the assignment component. Performance rubric used in this research was holistic rubric, as presented in Table 2.

Tabel 2. Rubric of evaluation criteria

\begin{tabular}{|l|l|}
\hline Level & General Criteria \\
\hline 4 (very satisfactory) & $\begin{array}{l}\text { Showing understanding on the concepts, using appropriate } \\
\text { strategies, appropriate computation (calculation), good } \\
\text { explanation, appropriate diagram/table/chart, and going } \\
\text { beyond the expected problem solution. }\end{array}$ \\
\hline $\begin{array}{l}3 \text { (satisfactory with little } \\
\text { exception) }\end{array}$ & $\begin{array}{l}\text { Showing understanding on the concepts, using appropriate } \\
\text { strategies, mostly appropriate computation (calculation), } \\
\text { effective explanation, mostly correct diagram/table/chart, } \\
\text { and meeting the expected problem solution }\end{array}$ \\
\hline $\begin{array}{l}2 \text { (rather satisfactory with } \\
\text { much exception) }\end{array}$ & $\begin{array}{l}\text { Showing understanding on most of the concepts, not using } \\
\text { appropriate strategies, mostly appropriate computation } \\
\text { (calculation), satisfactory explanation, and meeting most of } \\
\text { the expected problem solution. }\end{array}$ \\
\hline
\end{tabular}


1 (unsatisfactory)

Showing little, if any, understanding on the concepts, not using appropriate strategies, inappropriate computation (calculation), unsatisfactory explanation, incorrect diagram/table/chart, not meeting all of the expected problem solution

All of the information obtained by both scoring rubric and performance assessment and questionnaire was analyzed in both quantitative and qualitative ways.

\section{Results}

Implementation of Kirkpatrick's Evaluation Model was assessed in terms of the learning process for the subject of Initial Value and Boundary Condition Problems. The results of data analysis were elaborated for the four evaluation aspects. Each evaluation aspect was analyzed to obtain information on the students' competence for the subject of Initial Value and Boundary Condition Problems. Then, the data collected from each evaluation levels were evaluated using different instruments.

\subsection{Evaluation of reaction}

A learning process or lecture process is considered successful when the students feel satisfied with the strategies used by the lecturer, learning media, and assessment system. Partner (2009) suggests that the interest, attention and motivation of the participants are critical to the success of any training program; people learn better when they react positively to the learning environment. Based on the notion, it can be concluded that the success of a learning process is inseparable from the interest, attention, and motivation of the students to follow the lecture. The students can learn in better way when they react positively to the learning environment. Students' satisfaction to a learning process is studied based on various aspects, namely, material, available facility, strategy of material elaboration used by the lecturer, and the existing learning media.

The level of students' satisfaction to the learning process is presented in Figure 1. The data show that percent satisfaction in class A was 58,06\%, indicating that 58,06\% of the students felt very satisfied with the learning process, $29,03 \%$ of the students felt satisfied, $9,68 \%$ of the students felt rather dissatisfied, and 3,23\% of the students felt dissatisfied with the learning process. In class B, $48,39 \%$ of the students felt very satisfied; $29,03 \%$ of the students felt satisfied; $6,45 \%$ felt rather dissatisfied; and 3,23\% of the students felt dissatisfied with the learning process $_{20}$

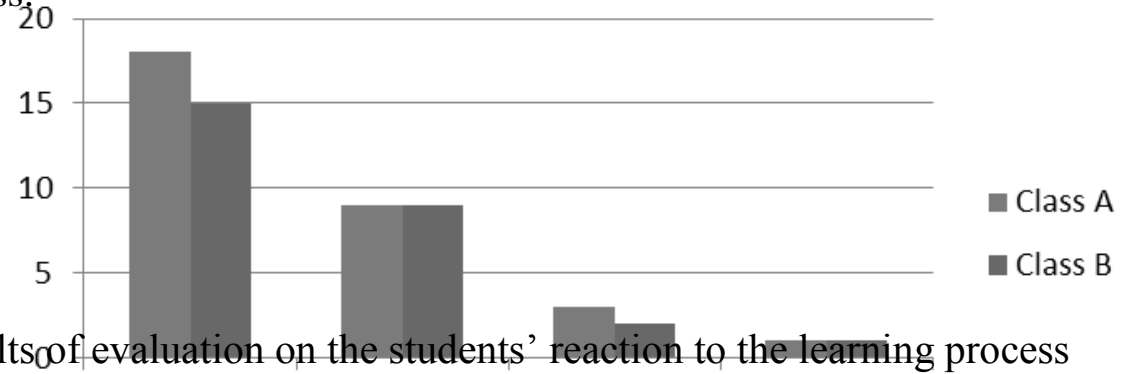

Figure 1. Resultsoof evaluation on the students' reaction to the learning process

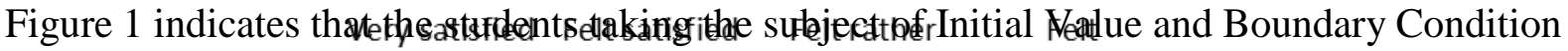
Problems reacted positively to the learning passisfieEvaldiatioinfibecame a basis for future improvement or for enhancement of teaching-learning process by the lecturer.

3.2 Evaluation on learning

Alternative assessment is important to assess the process dimension and learning outcome in the students; such outcome does not come from assessment by means of written tests. Performance assessment is also a part of alternative assessment, namely, real task situations, to provide useful feedback for the development of students' potentials. Some experts have criticized the use of traditional tests (paper and pencil test) in the learning process. Such a test 


\section{Macrothink Institute $^{\mathrm{TM}}$}

merely assesses scientific knowledge of the students. It cannot develop the students' potentials, particularly those related to competence in a certain subject.

Learning evaluation is necessary to measure effectiveness of a learning program. It involves three important aspects, namely, behavioral modification, improvement of knowledge, and improvement of skills displayed by the students. A learning process is said to be a failure when the three aspects could not be implemented or when they cannot bring about a change or improvement. The learning evaluation targets the learning output. Therefore, assessment of learning output makes use of performance assessment to determine knowledge the students have learnt, behavioral change, and skills that have been developed or improved.

Learning evaluation in Kirkpatrick's Evaluation Model was conducted by means of performance assessment using scoring rubric. Assessment rubric for individual students is presented in Table 3. Assessment criteria for scoring rubric as presented in Table 3 refer to those in Table 2. Learning of the Initial Value and Boundary Condition Problems was provided with the expectation that it could develop and uncover all of the students' potentials, since such competence is very useful for the students to stimulate or to model natural phenomena or daily-life phenomena.

Table 3. Assessment Rubric for the students' projects

\begin{tabular}{|c|c|}
\hline Criteria & Students \\
\hline Understanding of concepts & $\begin{array}{llllll}1 & 2 & 3 & 4 & 5 & 6\end{array}$ \\
\hline $\begin{array}{l}\text { Showing understanding on the concepts of the Initial Value } \\
\text { and Boundary Condition Problems }\end{array}$ & \\
\hline Validity of the materials delivered & \\
\hline Reasoning/Communication & \\
\hline Clear description on the answer & \\
\hline Good description on the answer & \\
\hline Good computation & \\
\hline Problem solving & \\
\hline Arranging a good algorithm & \\
\hline Good result of stimulation & \\
\hline Appropriate chart & \\
\hline
\end{tabular}

Learning evaluation was conducted on individual students for any changes or improvement in knowledge, attitude, and skills they have. Every student was assessed using rubric as presented in Table 3. The highest score in the assessment rubric was 32 while the lowest score was 8 . Rubric scores for the students in class A are presented in the following chart.

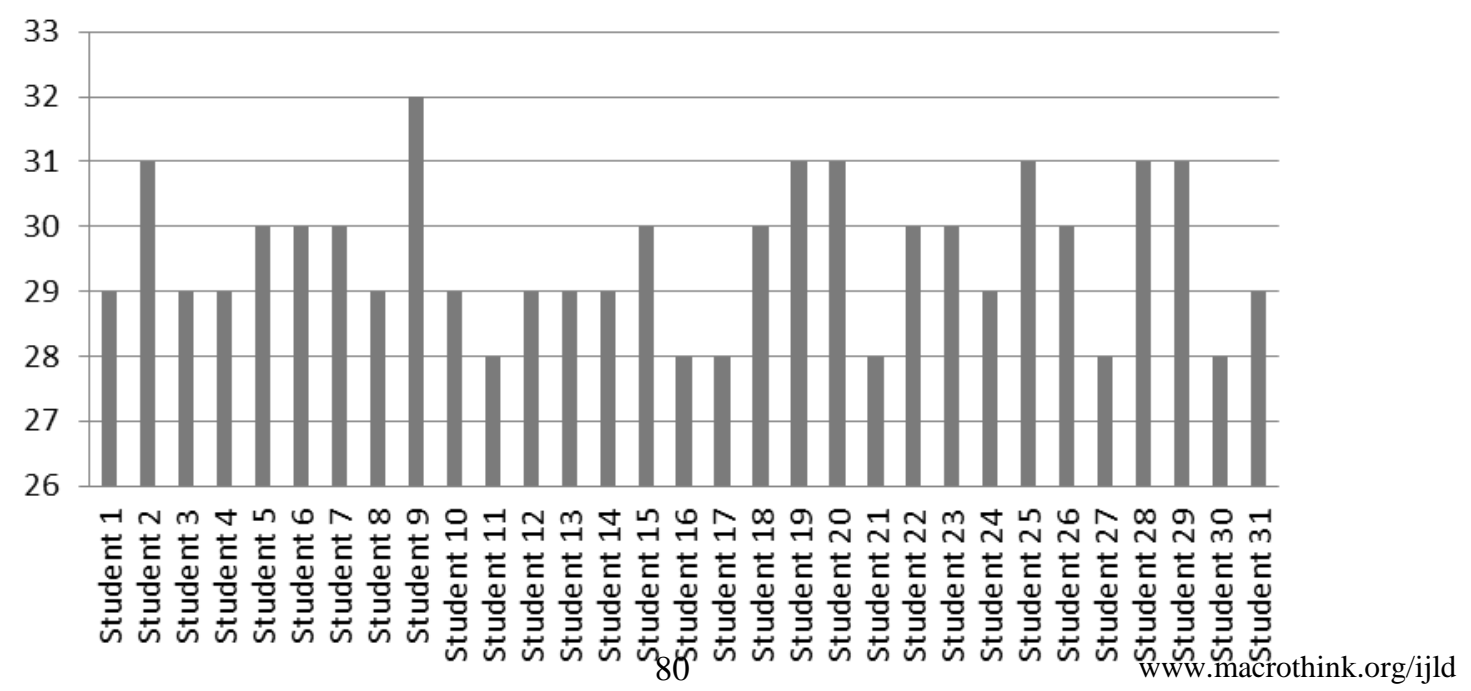


Figure 2. Evaluation of learning output in Class A students by means of performance assessment

Average score of the students was 29,55 or $92,33 \%$. This indicates that competence of the class A students in the subject of Initial Value and Boundary Condition Problems was very satisfactory. On the other hand, rubric scores for the students in class B are presented in the following chart.

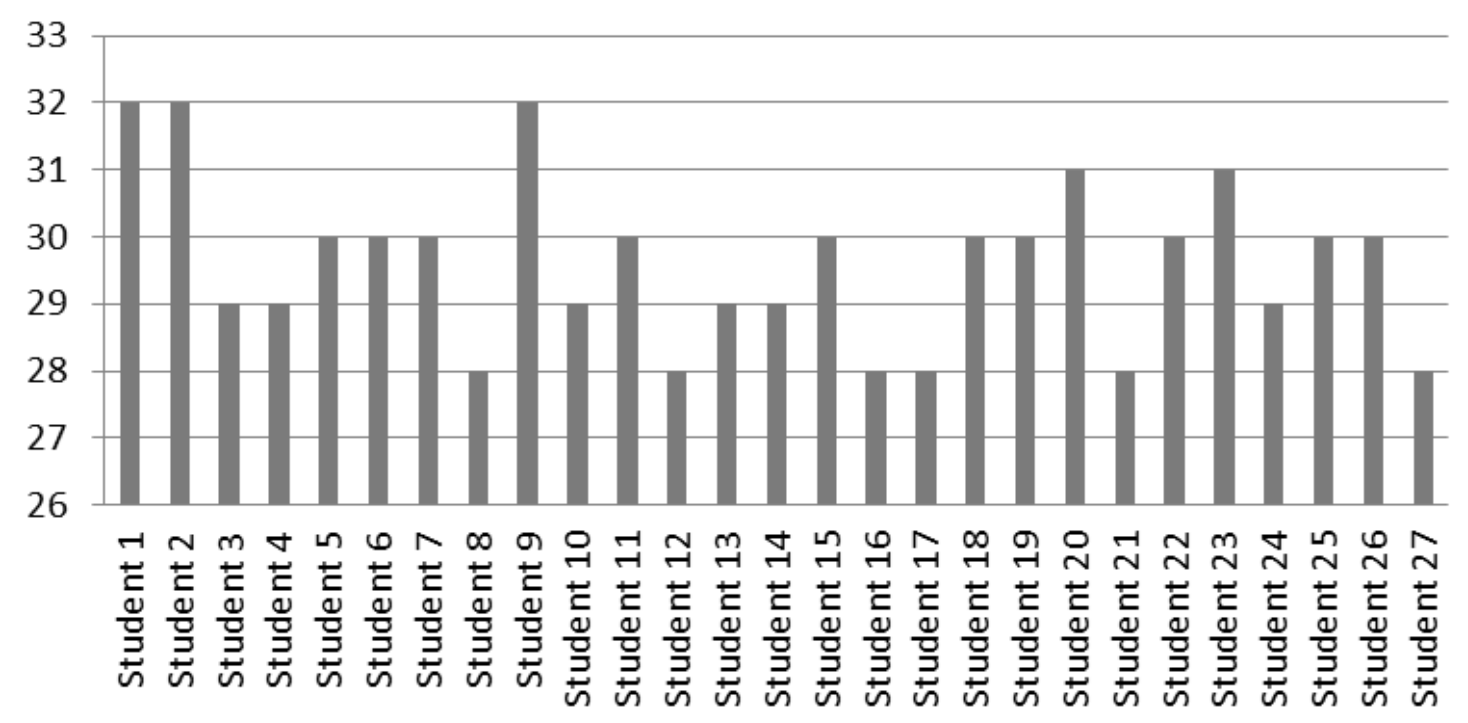

Figure 3. Results of learning evaluation on class B students by means of performance assessment. Average score for the students was 296.35 or $92,59 \%$

\subsection{Evaluation of behavior}

Behavioral evaluation, which was related to the learning process for the Initial Value and Boundary Condition Problems, was focused more greatly on the changes of behavior shown by the students in relation to benefits of the subject. The learning process is said to be successful when the students could implement materials of the Initial Value and Boundary Condition Problems in mathematic modeling based on the natural phenomena or daily-life phenomena. The evaluation was conducted by assessing the students' works in modeling the concepts of Initial Value and Boundary Condition Problems in relation to the natural phenomena or daily-life phenomena. An instrument was selected to assess the students' works in relation to the implementation of Initial Value and Boundary Condition Problems concepts. In this phase, the evaluation made use of scoring rubric for group presentation to obtain a description on the implementation of Initial Value and Boundary Condition Problems concepts. Scoring rubric used to guide the assessment is presented in the following Table 4. 
Tabel 4. Rubric scoring for the students' works in group presentation

\begin{tabular}{|c|c|c|}
\hline \multirow{2}{*}{$\begin{array}{l}\text { Criteria } \\
\text { Knowledge/Understanding on Concepts }\end{array}$} & Score & Total \\
\hline & $\begin{array}{llll}4 & 3 & 2 & 1\end{array}$ & \\
\hline $\begin{array}{l}\text { Suitable with the concepts of Initial Value and Boundary } \\
\text { Condition Problems }\end{array}$ & & \\
\hline Correct Mathematic model & & \\
\hline Interesting problems created & & \\
\hline Correct algorithm arranged & & \\
\hline Correct computation and stimulation & & \\
\hline Criteria & Score & Total \\
\hline \multicolumn{3}{|l|}{ Explanation clarity } \\
\hline \multicolumn{3}{|l|}{ Using adequate media } \\
\hline \multicolumn{3}{|l|}{ Interesting presentation of visualization } \\
\hline \multicolumn{3}{|l|}{ Collaboration of all group members } \\
\hline Answering any questions during discussion session & & \\
\hline
\end{tabular}

Assessment for the students' projects, namely writing and presenting article on modeling or computation that applied the concepts of Initial Value and Boundary Condition Problems, was conducted in a group basis. For the 6 students in class A, the results of students' projects are presented in Figure 3. Data were collected through direct observation when the students presented the articles they had written. Assessment for the students' presentation project was based upon the scoring rubric that had been formulated, and then summarized, as depicted in Figure 3. The highest score was 36 and the lowest one was 0 . Rubric for each aspect referred to the criteria of rubric assessment, as presented in Table 2.

Of the nine aspects assessed when the students presented their article on the applications of Initial Value and Boundary Condition Problem concepts in the natural phenomena or in daily-life phenomena, the highest score was 3,3 and the lowest one was 22 , with average score of 27,83 .

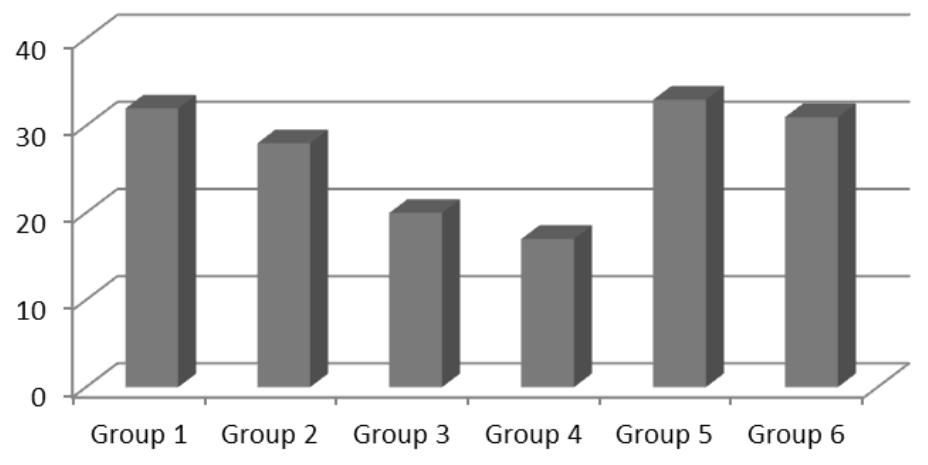

Figure 4. Assessment score for the group projects of class A students Average score for each aspect of assessment for the projects of class A students is presented in the following Figure 5.

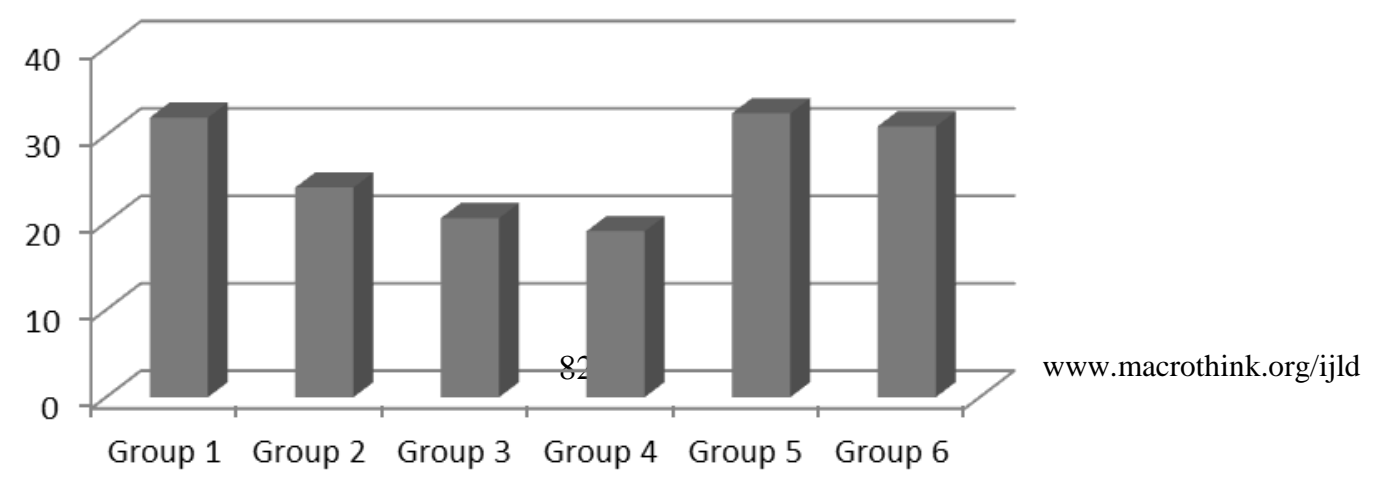


Figure 5. Average assessment score for the projects of class A students

The same assessment method was conducted in class B to obtain data on the students' performance related to the applications of the concepts of Initial Value and Boundary Condition Problem in natural phenomena or in daily-life phenomena. Of the nine aspects assessed in each group, the highest score was 29 while the lowest one was 26, with an average score of 28. Assessment scores for the students' projects related to the applications of Initial Value and Boundary Condition Problem concepts are presented in the following Figure 6.

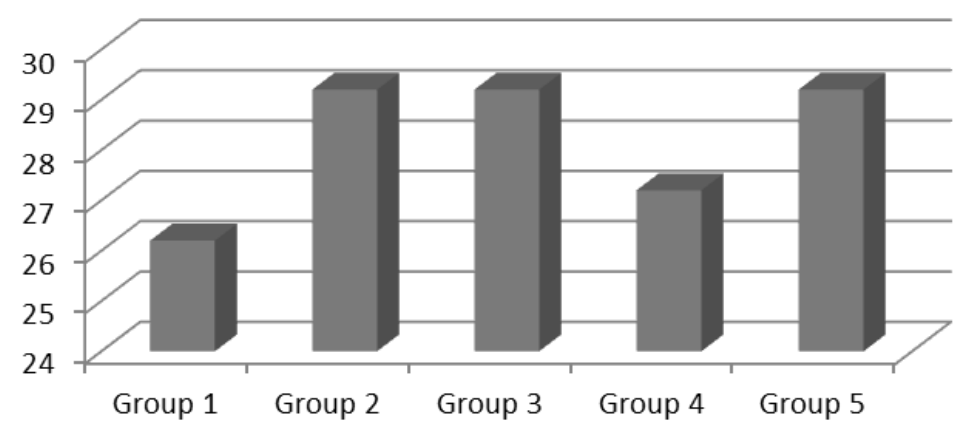

Figure 6. Assessment scores for the group projects of class A students

On the other hand, average scores for each aspect of assessment for the projects of class B students are presented in the following Figure 7.

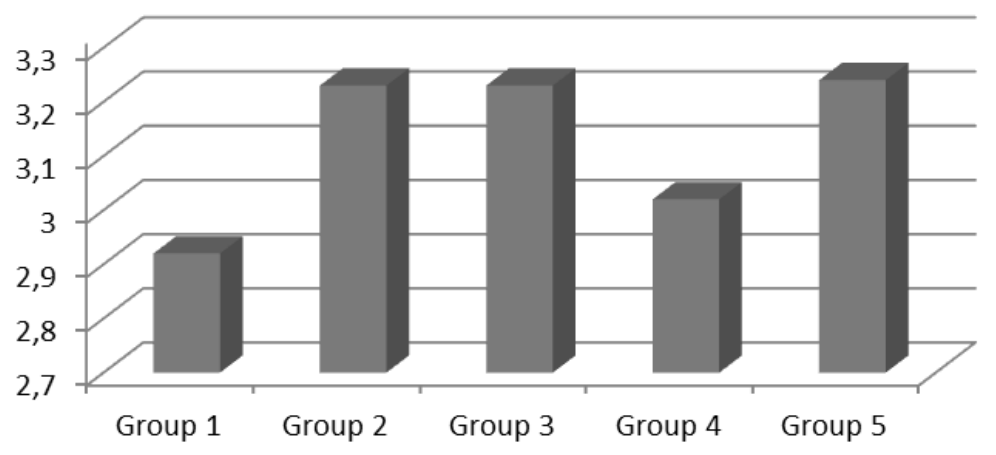

Figure 7. Average assessment score for the group projects of class B students

3.4 Outcome evaluation

Outcome evaluation is related to the outcome received by the students. The evaluation is said to be successful when the students got good academic grades. Academic grades of the students are presented in the following Table 5.

Table 5. Data of the Students' Academic Grades

\begin{tabular}{|l|l|l|l|l|}
\hline No & Class & Average & Standard Deviation & Criteria \\
\hline 1 & A & 83.84 & 6.63 & Very satisfactory \\
\hline 2 & B & 84.31 & 6.45 & Very satisfactory \\
\hline
\end{tabular}

Average academic grades of the students for the subject of Initial Value and Boundary Condition Problem as shown in Table 5 were very satisfactory. In other words, the students generally had a good understanding on the subject. 


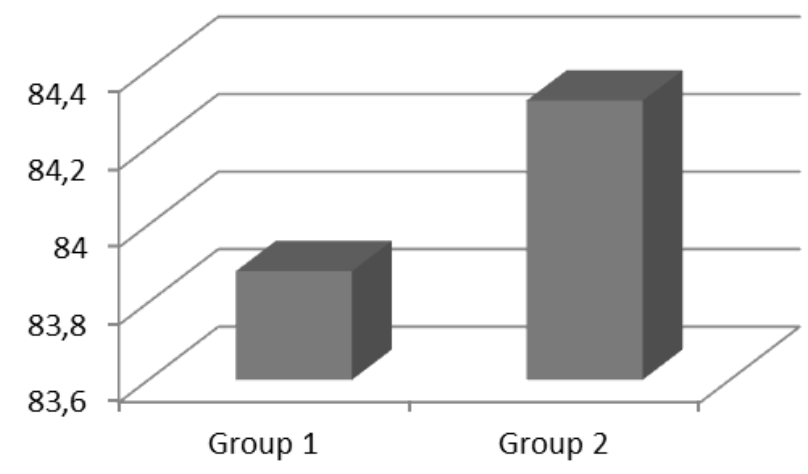

Figure 8. Average academic grades of the students for the subject of the Initial Value and Boundary Condition Problem

\section{Result}

The results of data analysis revealed that the implementation of Kirkpatrick's Evaluation Model based on the learning process for the subject of Initial Value and Boundary Condition Problems run in an expected way and provided a description on the overall competence of students. The students' understanding on the materials provided in the subject of Initial Value and Boundary Condition Problem was very satisfactory (high). Outcome (final grade) of the students informed their competence. This is because the evaluation models used during the course could reach all aspects of competence the individual students had. In addition, assessment for the subject was not limited to written test. It also involved performance assessment.

Given the characteristics of the subject of Initial Value and Boundary Condition Problems, which requires much computational work (computer stimulation), it is necessary to use a software program to assist the learning activities. In this research, learning activities made use of Maple software as a stimulatory tool. A software program was also used by the students who took level 1 to evaluate the Kirkpatrick's Evaluation Model. Results of the research, which are presented in Chart 1, showed that, in overall, the students felt satisfied or agreed with the learning model applied for the subject.

In general, the research showed that Kirkpatrick's Evaluation Model could be applied to evaluate a learning program of Initial Value and Boundary Condition Problems. It was because the four aspects in Kirkpatrick's Evaluation Model could describe the changes in attitude, behavior, skills, and learning outcome in the students who took the subject. In adaptation, the students began to be able to indicate all potentials they had. They perceived that anything they did in relation to the subject or the concept of Initial Value and Boundary Condition Problems would deserve an appreciation or a distinct valuation.

Evaluation for the subject of Initial Value and Boundary Condition Problems, when it comes to stimulation and modeling - either in relation to natural phenomena or in relation to daily-life phenomena - should be done with an model that could modify the students' behavior and attitude toward the subject characteristics. The lecturer could modify the existing scoring rubric model to adjust to the subject characteristics.

Evaluation of a learning program is better conducted in individual way by the lecturer or in an institutional way at the department level. This aims at improving the learning process and developing the students' potentials. The Kirkpatrick's Evaluation Model consists of four aspects of evaluation, which are helpful to obtain more information from the students. Each evaluation aspect involves different assessment model. Performance assessment is helpful for the students to familiarize their selves to showing all potentials they have. 
The first level in Kirkpatrick's Evaluation Model (Participant Reaction) for the learning program of Initial Value and Boundary Condition Problems was related to the students' satisfaction level when it comes to the subject materials, quality, and material delivery system by the lecturer, and the learning media. Therefore, evaluation model at this level was more greatly focused on measuring the students' satisfaction. The second level measured learning aspects related to the students' knowledge. At this level, students who took Initial Value and Boundary Condition Problems underwent assessment for their competence and knowledge by means of performance assessment. This was conducted to find out all competence the students had.

The second level in Kirkpatrick's Evaluation Model elaborated all of the assessment aspects in a thorough way by using clear criteria. Criteria of the conceptual understanding consisted of how the students showed their understanding on the concepts of Initial Value and Boundary Condition Problems and its material validity. With these criteria, the students' success was measured from the satisfaction with the Initial Value and Boundary Condition Problems materials. Mastery of the subject material was useful for the next activity, namely, formulation of logarithm and stimulation.

The third level in Kirkpatrick's Evaluation Model for the learning program of Initial Value and Boundary Condition Problems was important to measure the students' skill in applying the concepts when it comes to modeling of natural phenomena or daily-life phenomena. The students had presentation projects for the subject of Initial Value and Boundary Condition Problems. The project aimed at providing information on the students' mastery of the concepts they had learnt. The last level in Kirkpatrick's Evaluation Model for the learning program of Initial Value and Boundary Condition Problems was focused on the outcome of the academic activities achieved by the students.

The students' success was evident from the third level in Kirkpatrick's Evaluation Model. Criterion of assessment at this level was continuation of the first-level criterion, namely, use of the concepts in simulation and modeling. The students made a simulation model for one of the natural phenomena or daily-life phenomena by using the concepts of Initial Value and Boundary Condition Problems. Then, the results of computation were presented as an aspect of assessment in the specified scoring rubric.

Evaluation of the learning process was the main aspect to find out all of the students' competence. Kirkpatrick's Evaluation Model facilitated the lecturer or teaching staff in conducting a comprehensive evaluation on the potentials the students had. The subject of Initial Value and Boundary Condition Problems, which greatly involved computation and modeling, required an evaluation model that was able to explore the students' performance in a comprehensive way.

Kirkpatrick's Evaluation Model, which was applied for Initial Value and Boundary Condition Problems with its four levels of evaluation, described the students' competence. The level of mastery can be measured from a number of aspects with varied assessment systems. Such assessment systems could uncover all of the students' competence and potentials for each indicator of the subject.

Scoring rubric used for each level in the Kirkpatrick's Evaluation Model could motivate the students to tell what they knew about the subject of Initial Value and Boundary Condition Problems. Design of the learning process should consider the evaluation and assessment model to get a comprehensive description on the students' competence.

An assessment process, which is able to uncover all of the students' competence, can create an effective and efficient learning situation. This is because the students' activities during the learning process were more greatly focused on the ability to solve any learning problems or to reveal what they knew about the subject. When it comes to the subject of Initial Value and Boundary Condition Problems, which involved the use of IT, namely programming software, it 
is necessary to conduct an assessment for the students' projects or performance. Since the evaluation system merely focused on the written test, it is difficult to measure the students' success to gain competence for a subject.

In the learning process at the college level, the lecturer plays a role as an evaluator that serves to measure the way the learning objectives, which have been formulated, and the learning materials, which have been applied in the learning process, are achieved. As an evaluator for the learning process and outcome, the lecturer should follow up the students' achievement in continuous way. Information obtained from the evaluation provided feedback for the learning process. The feedback became a basis for improving and enhancing the learning process. In this way, the learning process would run in an optimum and effective way.

Evaluation was conducted by the lecturer for the subject of Initial Value and Boundary Condition Problems at the end or during the learning process. The lecturer did the evaluation by paying attention to the criteria of learning completeness the students met. Evaluation by the lecturer should have been conducted in a continuous way for each learning process. When the evaluation was conducted only at the end of learning process, the learning outcome could not actually describe the learning process itself. The evaluation should have been able to provide information on to what extent the learning objectives had been achieved. In an evaluation session, the evaluator should pay attention to aspects to be achieved, to the students, and to the scoring rubric.

\section{Limitation of the research}

The research was conducted by following the phases or levels in Kirkpatrick's Evaluation Model, but it is subject to some limitations. They include the number of sample, which consisted of only two classes. Observation was conducted for each aspect in the scoring rubric and the number of students participating in the research was a limiting factor. The research was conducted only in Mathematics Department, Faculty of mathematics and Natural Sciences, State University of Gorontalo with 58 respondents as the sample. Further research is expected to use more extensive population and sample.

\section{Implication}

Theoretical implication of the research finding is that Kirkpatrick's Evaluation Model provides information on the way to assess the students' competence in a whole way. Practical implication is that the Kirkpatrick's Evaluation Model is an alternative way for the lecturers to get a description on the students' competence in the subject of Initial Value and Boundary Condition Problems or in any other subjects.

This research shows that using Kirkpatrick's Evaluation Model for the learning process of Initial Value and boundary Condition Problems in Mathematics Department, Faculty of mathematics and Natural Sciences, State University of Gorontalo, learning activities of the students are found to be very effective and able to explore all of the students' competence.

The research gives a specific impact on the learning evaluation on any other subjects with the same characteristics in general. Assessment for each learning process is conducted in a different way to get an optimum description on the students' potentials, particularly those related to a certain subject. It is conducted to improve learning outcomes in the students.

\section{Conclusion}

Implementation Kirkpatrick's Evaluation Model in the learning program of Initial Value and Boundary Condition Problems is very effective to uncover the students' competence, particularly for a certain subject. Kirkpatrick's Evaluation Model is able to encourage the students to apply the concepts of Initial Value and Boundary Condition Problems, particularly when it comes to modeling and stimulation. The subject characteristics become the bases to 
determine the evaluation tools for learning. This is related to how all of the potentials the students have are uncovered. Students' understanding on a certain subject cannot be measured using written tests, but performance assessment is an alternative way to find out the students' competence in overall.

A learning process requires lecturers, who are able to teach in a good way and able to conduct evaluation in an effective way. Evaluation becomes an integral part of a program plan that must been specified in advance. Evaluation on a learning process is conducted in a comprehensive way, both for the learning process and for the learning outcome. Assessment of the learning process is conducted to find out the students' competence for certain indicators in the subject.

\section{Acknowledgement}

Thank you the chairman of the department of mathematics education faculty mathematics and natural sciences Gorontalo State University and students as respondents in this study.

\section{References}

Eko, P. W. (2010). Evaluasi program Pembelajaran.Yogyakarta: Pustaka Pelajar

Garfield, J.B. (1994). Beyond Testing and Grading Using Assessment to Improve Student Learning.

Griffin, P., \& Nix, P. (1991). Educational Assessment and Reporting. Sydney: Harcout Brace Javanovich Publisher.

Jin, Y., \& Raul, V. C. (2000). Conceptual evaluation and Policy Developments in Life long Learning. Germmany: UNISCO Institute for Lifelong Learning.

Johnson, R. L. (2009). Assessing Performance: Designing, Scoring, and Validating performance Tasks. New York: A Division of Guildford Publication, Inc.

Kirkpatrick, D.L. (1998). Evaluating Training Programs: The Four Levels. San Francisco: Berretp-Koehler Publisher, Inc.

Madaus, G, F., Scriven, M., \& Stuffebeam, D. L. (1993). Evaluations Models. Viewpoints on Educational and Human Services Evaluation. Boston: Kluwer-Nijhoff Publishing.

Mardapi, D. (1999). Pengukuran, Penilaian, dan Evaluasi. Papers Presented in the Junior Mathematics Learning Evaluation Upgrading To Core Math Teachers in Junior High MGMPs, Mathematics PPPG Yogyakarta. Yogyakarta, 8-23 November.

Mardapi, D. (2000). Evaluasi Pendidikan. In a paper presented at the National Education Convention. Jakarta: Jakarta State University, 19-23 September

Mardapi, D.2003. Kurikulum 2004 dan Optimalisasi Sistem Evaluasi Pendidikan di Sekolah. In a paper presented at the National Seminar on Competency-Based Curriculum 2004. Yogyakarta: Ahmad Dahlan University, 10 January

Mokhtari, K., Yellin, D., Bull, K., \& Montgomery, D. (1996). Portfolio Assessment in Teacher Education: Impact on Preserve Teachers' Knowledge and Attitudes. Journal Of Teacher Education, 47.(4)

Oliva, P. F. (1992). Developing the Curriculum. New York: Harper Collins Publishers.

Oriondo, L. L., \& Antonio, E. M. D. (1998). Evaluating Educational Outcomes (Test, Measurement, and Evaluation). Florentine St: Rex Printing Company.

Peterman, F. P. (2005). Designing performance assessment systems for urban teacher preparation. New Jersey London: Lawrence Erlbaum Associates, Publishers Mahwa.

Popham, W.J. (1995). Classroom Assessment. Boston: Allyn and Bacon.

Sriraman, B., \& English, L., (2010). Theories of mathematics education. New York: Seeking New Frontiers Springer Heidelberg Dordrecht.

Stark, J.S., \& Thomas, A. (1994). Assessment and program evaluation. Needham Heights: Simon \& Schuster Custom Publishing. 
Teodoro, V.D. (2011). Mathematical Modelling in Science and mathematics education. Computer Physics Communications. 182, 8-10.

Tut, M A. (2010). An Alternative Approach to Improve Mathematics Performance of fourth Graders: GA's in Mathematics Education. Proceedings Social and Behavioral Sciences, 2, 2046-2050 